Florida State University College of Law

Scholarship Repository

Scholarly Publications

Spring 2014

\title{
A Cost-Benefit Analysis of Sugary Drink Regulation in New York City
}

Shi-Ling Hsu

Florida State University College of Law

Follow this and additional works at: https://ir.law.fsu.edu/articles

Part of the Health Law and Policy Commons, Law and Society Commons, and the State and Local Government Law Commons

\section{Recommended Citation}

Shi-Ling Hsu, A Cost-Benefit Analysis of Sugary Drink Regulation in New York City, 10 J. FOoD L. \& PoL'Y 73 (2014),

Available at: https://ir.law.fsu.edu/articles/490

This Article is brought to you for free and open access by Scholarship Repository. It has been accepted for inclusion in Scholarly Publications by an authorized administrator of Scholarship Repository. For more information, please contact efarrell@law.fsu.edu. 


\title{
A COST-BENEFIT ANALYSIS OF SUGARY DRINK REGULATION IN NEW YORK CITY
}

\author{
Shi-Ling Hsu*
}

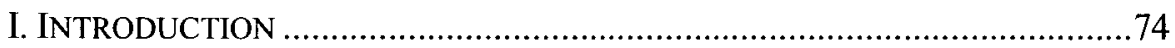

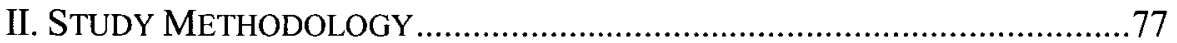

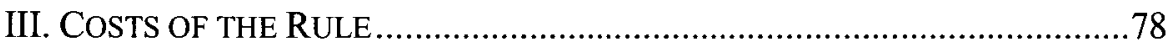

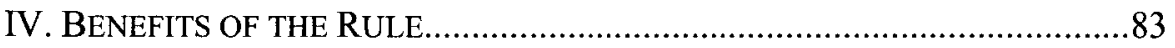

A. Approach One: Costs of Type 2 Diabetes and Coronary

Heart Disease Attributable to Sugary Drink Consumption ........85

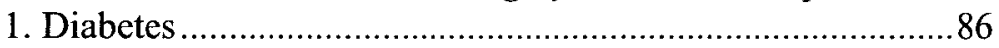

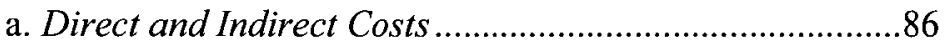

b. Costs of Premature Death.................................................91

c. A Lower-Bound Estimate of the Costs of Diabetes ..........92

2. Coronary Heart Disease...................................................92

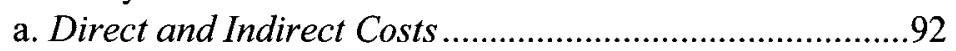

b. Costs of Premature Death.................................................96

c. A Lower-bound Estimate of Costs of Coronary Heart

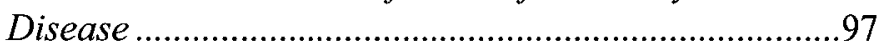

3. Total Direct and Indirect Costs, and Cost of Premature

Deaths Attributable to Sugary Drink Consumption.

B. Approach Two: Costs of Obesity Attributable to Sugary

Drink Consumption ...

* Larson Professor of Law, Florida State University College of Law. This Article is in part the result of the collective work of myself and law students enrolled in a seminar, Cost-Benefit Analysis in Environmental Law, offered at the Florida State University College of Law in 2013. I would thus like to acknowledge the research and contributions of Kevin Schneider, Tyler Fleming, Shannon Mathews, Ian Carnahan, and Kaitlin Monaghan. I would also like to acknowledge the help and comments of Teresa Fung, and the research assistance of Kevin Alford and Olivia Walker. All errors are my responsibility alone. 


\section{INTRODUCTION}

New York City Mayor Bill de Blasio spent much of his time during his successful 2013 campaign positioning himself as the populist candidate, pointedly contrasting himself with the outgoing mayor, billionaire Michael Bloomberg. ${ }^{2}$ There is one Bloomberg initiative, however, that de Blasio has committed to carry forward: the city-wide size restriction on sales of "sugary drinks," most commonly, carbonated sodas. ${ }^{3}$ On city public health issues such as the sugary drink policy, the populist de Blasio and the billionaire Bloomberg would appear to have much in common. "People are dying every day, this is not a joke," remarked Bloomberg in striking a populist tone in defense of his initiative. ${ }^{4}$

In September of 2012 the New York City Board of Health adopted the "Portion Cap Rule," adding section 81.53 to the New York City Health Code prohibiting the sale of "sugary drinks" in containers exceeding sixteen ounces. ${ }^{5}$ A "sugary drink" is defined as a "carbonated or noncarbonated beverage that is non-alcoholic, ... sweetened ... with sugar or another caloric sweetener,... has greater than 25 calories per 8 [fluid] ounces, ... and does not contain more than 50 percent of milk or milk substitute by volume." The Portion Cap Rule would have applied to "food service establishments," defined as "a place where food is provided for individual portion service directly to the consumer whether such food is provided free of charge or sold, and whether consumption occurs on or off the premises or is provided from a pushcart, stand or vehicle." "This would have included restaurants, movie theaters, sports venues, coffee shops, pizza shops, delicatessens, food trucks, and street carts. ${ }^{8}$

A lawsuit challenging the Portion Cap Rule was filed less than one month later by a broad coalition of groups, including the National

2. Michael Grynbaum, Taking Office, de Blasio Vows to Fix Inequity, N.Y. TIMES, Jan. 1, 2014, http://www.nytimes.com/2014/01/02/nyregion/bill-de-blasio-inauguration. html? $\mathrm{r}=0$.

3. Kate Taylor, De Blasio Names Ex-Bloomberg Official as Health Chief, But Vows New Approach, N.Y. TimES, Jan. 16, 2014, http://www.nytimes.com/ 2014/ $01 / 17 /$ nyregion/de-blasio-names-ex-bloomberg-official-as-health-chief-but-vows-newapproach.html.

4. Ross Barkan, Michael Bloomberg Defends Soda Ban on Grounds that 'People Are Dying Everyday,' N.Y. OBSERVER, Mar. 11, 2013, http://observer.com/ 2013/03/michael-bloomberg-defends-soda-ban-on-grounds-that-people-are-dyingeveryday/.

5. N.Y.C., N.Y. HEALTH CODE $\S 81.53$ (2012).

6. N.Y.C., N.Y. HEALTH CODE $\$ 81.53$ (a) (2012).

7. N.Y.C., N.Y. HEALTH CODE $\$ 81.03(\mathrm{~s})(2012)$.

8. N.Y.C., N.Y. HEALTH CODE $\$ \S 81.53$ (b)-(c) (2012). 
Restaurant Association, the National Association of Theatre Owners of New York State, and the New York Statewide Coalition of Hispanic Chambers of Commerce. ${ }^{9}$ Cries of a Bloomberg "nanny state" rang out across the media and blogosphere. ${ }^{10}$ Criticism was not limited to industry groups and right-leaning media: the Portion Cap Rule was also criticized by Hazel Dukes, the President of the NAACP New York State Conference, and others putatively concerned with public health and communities of color, on the grounds that this policy deprived consumers of freedom of choice, that it was not enough, and that it discriminated against minorityowned businesses." This latter opposition was surprising since excess sugary drink consumption has been tied to elevated rates of obesity, ${ }^{12}$ especially in communities of color, which have been particularly hard-hit. ${ }^{13}$ At any rate, the Portion Cap Rule remains in legal limbo. New York Supreme Court Judge Milton Tingling enjoined New York from implementing it, declaring section 81.53 to be invalid, ${ }^{14}$ and a state appeals court has upheld that ruling. ${ }^{15}$ The New York State Court of Appeal will

9. New York Statewide Coal. of Hispanic Chambers of Commerce v. New York City Dep't of Health \& Mental Hygiene, No. 653584/12, 2013 WL 1343607, at *1-2 (N.Y. Sup. Ct. Mar. 11, 2013).

10. Karen Harned, The Michael Bloomberg Nanny State in New York: A Cautionary Tale, FORBES, May 10, 2013, http://www.forbes.com/sites/realspin/2013/05/10/themichael-bloomberg-nanny-state-in-new-york-a-cautionary-tale/; Katrina Trinko, Soda Ban? What About Personal Choice?, USA TODAY, Mar. 10, 2013, http://www.usatoday.com/story/opinion/2013/03/10/soda-ban-what-about-personalchoice-column/1977091/.

11. Hazel N. Dukes, Sugar-Sweetened Beverages Ban: Misdirected and ShortSighted, HUFFINGTON POST, Aug. 27, 2012, http://www.huffingtonpost.com/hazel-ndukes/ny-soda-ban_b_1834816.html; Letitia James \& Melissa Mark-Viverito, Why the Soda Ban Won't Work, THE HufFington POST, Aug. 27, 2012, http://www.huffington post.com/letitia-james/nyc-soda-ban_b_1652169.html.

12. See, e.g., Adolfo J. Ariza et al., Risk Factors for Overweight in Five- to SixYear-Old Hispanic-American Children: A Pilot Study, 81 J. URB. HEALTH: Bull. N.Y. ACAD. MED. 150, 150 (2004); see also infra, notes 43-45 and accompanying text.

13. See, e.g., N.Y. STATE DEP'T OF HEALTh, BEHAVIORAL RISK FaCtoR SURVEILlANCE SYSTEM BRIEF No. 13043 (2011), available at http://www.health.ny.gov/statistics/brfss/reports/docs/1304_overweight_and_obesity.p df.

14. New York Statewide Coal. of Hispanic Chambers of Commerce, 2013 WL 1343607 at $* 20-21$.

15. Matter of New York Statewide Coal. of Hispanic Chambers of Commerce v. New York City Dep't. of Health \& Mental Hygiene, 970 N.Y.S.2d 1, 3 (N.Y. Sup. Ct. 2013). 
review the rule in $2014 .{ }^{16}$ The biggest legal problem with the Portion Cap Rule appears to be that it needed to be legislatively enacted by the New York City Council, and not just implemented by administrative fiat. ${ }^{17}$

The problem of obesity is quite serious, however, such that public health officials now describe it as an "epidemic."18 Of particular concern are new findings that obesity seems to be locked in at a surprisingly young age - most children who are obese by the age of eleven remain obese for the rest of their lives. ${ }^{19}$ Sugary drinks, while not the entire cause of the epidemic, provide a large infusion of calories for a large fraction of the population, and appear to be a major contributor to obesity. ${ }^{20}$ Moreover, sugary drink consumption and obesity give rise to other, more serious health conditions, including type 2 diabetes and coronary heart disease. ${ }^{21}$

Given the continuing importance of the problem, some quantitative analysis would appear to be useful, especially in light of the incendiary rhetoric surrounding the Portion Cap Rule. This article seeks to refocus the debate on sugary drink regulation by setting forth a rough cost-benefit analysis of sugary drink regulations, such as the New York City Portion Cap Rule. This article seeks to answer the following question: if the Portion Cap Rule had been implemented, would it likely have generated more monetizable health benefits than it would cost sellers of sugary drinks? Of course, this is not the only criteria by which the Portion Cap Rule should ultimately be judged. Non-monetizable ethical concerns shadow the outcome of any cost-benefit analysis, and the sugary drink ban raises quite a few of them. Most of the benefits of sugary drink consumption are derived from the extraordinarily high profit margins on sugary drinks such as carbonated soda, while providing virtually no nutritional value to consumers. However, given the amount of controversy generated by the Portion Cap Rule, some cooler discussion would appear to

16. Michael Grynbaum, New York Soda Ban to Go Before State's Top Court, NY TiMES, Oct. 17, 2013, http://www. nytimes.com/2013/10/18/nyregion/new-york-sodaban-to-go-before-states-top-court.html.

17. Matter of New York Statewide Coal. of Hispanic Chambers of Commerce, 970 N.Y.S.2d at 10-12 (stating that "[i]n sum, we find that... the Board of Health overstepped the boundaries of its lawfully delegated authority when it promulgated the Portion Cap Rule to curtail the consumption of soda drinks. It therefore violated the state principle of separation of powers").

18. Ctrs. for Disease Control \& Prevention, The Obesity Epidemic, http://www.cdc.gov/CDCTV/ obesityEpidemic/index.html (last visited May 19, 2014).

19. See, e.g., Gina Kolata, Obesity Is Found to Gain.Its Hold in Earliest Years, N.Y. TIMES, Jan. 30, 2014, http://www.nytimes.com/2014/01/30/science/obesity-takes-holdearly-in-life-study-finds.html?_r $=0$.

20. See, e.g., Ariza et al., supra note 11.

21. CTRS. FOR DISEASE CONTROL \& PREVENTION, supra note 17. 
be warranted. Some effort to consider the costs and benefits of sugary drink regulation may provide a different perspective on the muchtrumpeted liberty of palate.

This article performs a cost-benefit analysis for New York City not only because of the controversy surrounding the Portion Cap Rule, but also because a public health initiative aimed at reducing sugary drink consumption and concomitant obesity seems especially appropriate for a major city. Many public health programs are carried out at the local level, such that addressing a problem such as obesity in a holistic fashion would best be undertaken by local government. This article aims to provide guidance for local governments considering sugary drink regulation.

\section{STUDY METHODOLOGY}

This study is limited in an important way: it estimates the total profits derived from sales of sugary drinks in New York City (the reduction of these sales would be the compliance costs), and the total health costs attributable to sugary drink consumption (the reduction of these costs would be the benefits). In other words, this study does not actually perform a cost-benefit analysis of the Portion Cap Rule itself, but rather of $a$ total ban of sugary drinks within New York City. While such a total ban is impractical, it helps to place some perspective on the trade-offs of any sugary drink restriction for a discrete jurisdiction such as New York City. Undertaking this larger but simpler analysis also avoids the need to guess at the effectiveness of the Portion Cap Rule in reducing sugary drink consumption. Whether the Portion Cap Rule would induce people to consume less soda, or whether it would induce people buy multiple drinks or cross the street and buy a large soda from a non-regulated vendor, is a matter that would require too much conjecture, and would, in the end, be unlikely to change the conclusion of this analysis.

This simplified approach can also be justified because if an epidemiological link between sugary drink consumption and health outcomes can be made, then it does not matter how effective the Portion Cap Rule would actually be. If the health benefits of a total ban outweigh the compliance costs of a total ban, then any measure short of a total ban is also likely to generate net benefits. In other words, this analysis assumes that both compliance costs and health benefits scale linearly with effectiveness of any regulatory attempt; if the Portion Cap Rule managed to reduce consumption by twenty percent, it would reduce both sugary drink profits and sugary drink-induced health costs by twenty percent. To the extent that sugary drink consumption contributes to health costs, this assumption seems very reasonable. The only goal is thus to determine if 
generally, the compliance costs of sugary drink restrictions are greater than health benefits.

The approach of this analysis is as follows: the costs of sugary drink regulation are estimated as the total profits of sugary drink sales in New York City, so that a sugary drink ban will result in a loss of these profits as a societal cost. As discussed below, this analysis will only focus on certain sellers of sugary drinks. The benefits of the sugary drink regulation are estimated as the health costs attributable to sugary drink consumption, so that a sugary drink ban will result in health benefits in the form of avoided illness, medical treatment costs, lost productivity, and premature mortality. Working from national data on the health costs of obesity, type 2 diabetes, and coronary heart disease (CHD), this analysis scales down in two stages: (i) calculating the fraction of national health costs specific to New York City, and (ii) calculating the fraction of these New York City-specific costs attributable to sugary drink consumption. In addition, this analysis estimates the number of premature deaths attributable to sugary drink consumption. The City of New York provides statistics on deaths and underlying causes, but again, some scaling-down is required to determine which of those deaths can be attributed to sugary drink consumption.

\section{COSTS OF THE RULE}

This article estimates the economic cost of sugary drink regulation as the lost profits from prohibited sales of sugary drinks. I ignore any nutritional and caloric benefits of sugary drinks; a plethora of healthier sources of caloric intake exist. I also do not attempt to estimate the consumer's surplus of sugary drink regulation. There no doubt exists some hedonic benefit to the taste of a sugary drinks; so, too, with cigarettes. At least for sugary drinks there exist low-calorie substitutes, such as diet drinks and perhaps even just plain water. In light of the possibility of substitution, the loss in consumer's surplus by having to switch from a sugary drink to a diet drink is assumed to be small.

In fact, if there is a bias in the costs of this analysis, it is to overestimate the costs to sugary drink sellers. If a total or partial ban on sugary drink sales were implemented, there would likely be a great deal of substitution of diet drinks, which would not be covered by sugary drink regulation (the Portion Cap Rule did not). This substitution would recoup much of the lost profits to sellers, as almost every sugary drink seller also sells diet drinks.

Sugary drinks are sold by many different kinds of sellers, but this analysis focuses only on three: (i) full-service restaurants, (ii) limitedservice restaurants, and (iii) convenience stores. There is reason to believe that the costs would be concentrated in these three types of establishments, 
as they are the primary sellers of sugary drinks that are dispensed through fountains. Movie theaters also dispense sugary drinks from fountains, and in fact account for about twenty percent of theater profits. ${ }^{22}$ However, the profits for New York City's thirty-nine theaters from sales of sugary drinks are so small - under this analysis, two orders of magnitude smaller than the overall total estimate - that they are excluded from this analysis as insignificant. $^{23}$ Obviously, movie theater owners would disagree: the National Association of Theater Owners cared enough to join in the lawsuit challenging the Portion Cap Rule. But in terms of societal gains and losses from sugary drink consumption, movie theater profits do not register a large economic impact.

This analysis also excludes upstream profits, such as those of drink manufacturers such as the Coca-Cola Company. They are substantial: Coca-Cola reported 2012 net operating revenues of about $\$ 48$ billion, with net income of $\$ 9.02$ billion, yielding a net profit margin of $18.8 \%{ }^{24}$ But the profits of Atlanta-based Coca-Cola and other manufacturers are external to New York City, and are thus excluded from the cost side of this analysis.

22. National Association of Theater Owners Executive Director Robert Sunshine was quoted as saying that "[s]oda accounts for 20 percent of theater profits." Chris Dolmetsch \& Henry Goldman, New York Soda Size Limit Statute Barred by State Judge, BLOOMBERG NEwS, Mar. 11, 2013, http://www.bloomberg.com/news/2013-0311/new-york-city-soda-size-limitations-barred-by-state-court-judge.html.

23. There are thirty-nine movie theaters in New York City with a total of 250 screens. This figure was obtained by visiting the website NYC.com, which allows for searching for movie theaters by neighborhood. By searching in all neighborhoods offered in the drop-down menu, we were able to survey all thirty-nine theaters and ascertain the number of screens for each theater. Revenues for these New York City movie theaters are unknown, but revenues for AMC Entertainment's 4988 screens across the United States were about $\$ 2.65$ billion, generating pre-tax profits of about $\$ 58$ million. AMC ENTERTAINMENT INC, FORM 8-K, CURRENT REPORT, FILED WITH THE UNITEd STATEs Securities and EXChange COMmission PuRsuant to $§ 13$ OR $§ 15$ (D) OF THE SECURITIES EXCHANGE ACT (Mar. 13, 2013), available at. http://investor.amctheatres.com/Cache/16284513.pdf?IID $=4171292 \& F I D=16284513 \&$ $\mathrm{O}=3 \& O S I D=9$. This translates into a profit of about $\$ 11,630$ per screen. Assuming that twenty percent of New York City theaters' profit is derived from sales of sugary drinks, New York City's 250 screens only derive a total profit of about $\$ 580,000$ from the sales of sugary drinks.

24. The Coca-Cola Company, Annual Report Pursuant to $\S 13$ OR $\S 15$ (D) OF THE SECuRITIES Exchange ACt OF 1934, For FisCal YeAR ENDING DECEMBER 31, 201229 (Item 6: Selected Financial Data) (Feb. 27, 2013), available at http://ir.thecoca-colacompany.com/phoenix.zhtml?c=94566\&p=irol-sec. The profits of Coca-Cola include profits from Dasani, bottled water that would not be part of any sugary drink regulation, and do not contribute to adverse health outcomes. 
From the local, retail perspective, this analysis focuses on profits from selling sugary drinks dispensed from soda fountains because those profits are exceptionally high, while those from packaged sodas are generally very low. Profit margins on fountain-dispensed sugary drinks are very high. The best estimate of the average price of a fountain-dispensed sugary drink served in New York City is $\$ 2.53 .{ }^{25}$ A typical cost of the syrup for a twelve ounce soda is about $\$ 0.21 .^{26}$ Allowing liberally for another $\$ 0.05$ for transportation costs, the cost of cups, lids, and straws, and for a fraction of personnel time, yields an estimated profit margin of about ninety percent.

By contrast, the retail profit margin on packaged sugary drinks (not fountain-dispensed) appears to be exceptionally low. Data on the retail profitability of sugary drinks outside of full-service and limited-service restaurants is spotty, but the available information strongly suggests that the profit margin on bottled drinks and drinks in cans is miniscule in comparison with fountain-dispensed drinks. For example, in 2009, the warehouse retailer Costco announced it would stop selling Coca-Cola products, a stunning announcement from the world's largest warehouse retailer involving the world's largest drink manufacturer. ${ }^{27}$ For a firm with Costco's very small profit margin $-2.5 \%{ }^{28}$ - a decision (which was eventually reversed) to discontinue sales of Coca-Cola products is testimony to the infinitesimal margins enjoyed by retailers of Coca-Cola. If Costco prices are close to wholesale - and the 2009 incident suggests it is - then comparing Costco prices and New York City retail prices could reveal at least a rough estimate of profit margins. Costco Business Delivery, the company arm specializing in delivering Costco bulk products to retail businesses, advertises that it will sell a thirty-two-pack of twelve ounce cans of Coca-Cola for $\$ 12.18,{ }^{29}$ or an average of $\$ 0.38$ per can. The 2013 Statistical Yearbook of Non-Alcoholic Beverages reports an average

25. See Data Shows Soft Drink Price Highly Variable Throughout Country, REUTERS, Apr. 7, 2008, http://www.reuters.com/article/2008/04/07/idUS109820+07Apr-2008+BW20080407; See also For Some, Restaurant Soft Drink Price Spike Tough to Swallow, GANNETT News SERV., Nov. 12, 2012, http://www.wtsp.com/ rss/article/282701/250/For-some-soft-drink-price-spike-tough-to-swallow.

26. See Home Soda Fountains, MARK POWERS \& Co., http://www.markpowers-andcompany.com/Page_Home Fountain.htm (last visited May 19, 2014); Wilton Marburger, Costing Out Soda \& Free Refills - How to Price Soda, PATE Dawson Co., http://www. pdco.com/node/88289 (last visited May 19, 2014).

27. Bruce Watson, Costco Yanks Coca-Cola From its Shelves, but Don't Cry for Coke, DAILYFINANCE, Nov. 18, 2009, http://www.dailyfinance.com/2009/11/18/costcoyanks-coca-cola-from-its-shelves-but-dont-cry-for-coke/.

28. $I d$.

29. Costco, http://www2 costco.com (last visited May 19, 2014). 
retail price in New York City of $\$ 3.49$ per twelve-pack, ${ }^{30}$ or $\$ 0.29$ per can. This back-of-the-envelope calculation obviously does not represent economic realities, as New York soda vendors have clearly figured out a way to avoid losing money selling Coca-Cola and other sugary drinks. But even such a rough order of magnitude calculation suggests that the profit margins are very, very small. It is particularly revealing that while New York City residents suffer a high cost of living, ${ }^{31}$ they still pay about the same amount for packaged soda as do their counterparts in cheaper cities such as Dallas, Phoenix, and Minneapolis, and in fact less than the average American city-dweller. ${ }^{32}$ This suggests that New York City retailers of Coca-Cola enjoy very low economic leverage and derive very little profit from selling sugary drinks such as Coca-Cola.

Finally, even if New York City-specific retail and distributor profits were to be included, it would not be likely to change the results. If the roughly $\$ 9$ billion profits of Coca-Cola were spread evenly throughout the country and New York City contributed its population's share, Coca-Cola's net profits for New York City would be about $\$ 240$ million. ${ }^{33}$ Nationwide, Coca-Cola holds about a thirty-five percent market share for packaged drinks. $^{34}$ If we assumed unreasonably liberally that retailers and distributors were taking as large a chunk of the profits as all drink manufacturers such as Coca-Cola, that would still only add about $\$ 750$ million to the cost side of the ledger which, as will be seen below, would not change the outcome of this analysis.

30. Beverage Digest, Statistical Yearbook of Non-Alcoholic Beverages, 2013160 (Table F-1) (on file with author).

31. See, e.g., Jason McCormick, 10 Most Expensive Places to Live in the U.S., CBS MONEYWATCH, Apr. 5, 2013, http://finance.yahoo.com/news/10-most-expensiveplaces-to-live-in-the-u-s-163648923.html.

32. BEVERAGE DIGEST, supra note 29, at Table F-2 (showing average retail prices for soda for many U.S. cities; shows New York City prices as a slightly below the United States average of $\$ 3.72$ per twelve pack).

33. The population of New York City in 2012 was estimated by the United States Census Bureau to be $8,336,697$. U.S. Census Bureau, State \& CounTY QUICKFACTS, NEW YORK (CITY), NEW YORK, http://quickfacts.census. gov/ $\mathrm{qfd} / \mathrm{states} / 36 / 3651000 . \mathrm{html}$ (last visited May 19, 2014). The population of the United States in 2012 was estimated to be $313,873,685$. U.S. CENSUS BUREAU, STATE \& COUNTY QUICKFACTS, USA, http://quickfacts.census. gov/qfd/states/00000.html (last visited May 19, 2014). Taking this fraction, 0.0266 , and multiplying it by Coca-Cola's total profits of $\$ 9$ billion, yields an estimated New York City-specific profit of $\$ 240$ million.

34. BeVERAGE DigeSt, supra note 29 , at 55 . 
According to the 2007 U.S. Census ${ }^{35}$ New York has 7265 full-service restaurants ${ }^{36}$ (which include steakhouses and pizza parlors, ${ }^{37}$ in addition to New York's famously expensive restaurants), and 5427 limited-service (mostly fast-food) restaurants. ${ }^{38}$ Total revenues were approximately $\$ 7.48$ billion and $\$ 2.94$ billion, respectively. ${ }^{39}$ Approximately $6 \%$ of revenues of full-service restaurants are from non-alcoholic beverage sales ${ }^{40}$ which is assumed to be sugary drinks, and $4 \%$ of revenues of limited-service restaurants are derived from the sale of sugary drinks. ${ }^{41}$ Assuming a $90 \%$ profit margin (as derived above), the profits from sugary drink sales from full-service and limited-service restaurants in New York City are estimated to be $\mathbf{\$ 4 0 4}$ million and $\mathbf{\$ 1 0 6}$ million, respectively.

There were 554 convenience stores in New York City in 2007, with total revenues of $\$ 241,787,000 .^{42}$ Nationally, sales of "cold, dispensed drinks" - sugary drinks from fountains - account for about $11.3 \%$ of convenience store sales ${ }^{43}$ suggesting (if national numbers can be applied to New York City convenience stores) that about \$25 million of convenience store revenue in New York City can be attributed to the sale of cold, dispensed drinks. ${ }^{44}$

All of these calculations are set forth in tabular form below. The total costs, in terms of foregone local profits, of a ban on selling sugary drinks in New York City, is estimated to be roughly $\$ 534$ million.

35. This analysis uses 2007 Census data because more recent data is not available. Of necessity, this analysis assumes negligible change in the number of establishments between 2007 and the years in which other data are collected for this study.

36. U.S. CENSUS BUREAU, FACTFINDER QUERY ON JANUARY 24, 2014 (printed query on file with author).

37. Id.

38. Id.

39. Id. The more precise figure reported for full-service restaurants was $\$ 7,484,339,000$, and for limited-service restaurants was $\$ 2,937,078,000$.

40. Ciji A. Tlapa, Richard K. Miller, \& Kelli Washington, The 2010 RESTAURANT, FoOd \& Beverage MARKET RESEARCH HaNdBoOK 20 (2011), available at http://lgdata.s3-website-us-east-1.amazonaws.com/ docs/160/210698/The_2010_ Restaurant,_Food_\&.pdf. In full-service restaurants. $15 \%$ of revenues are from sales of alcoholic beverages, leaving $6 \%$ from non-alcoholic beverages. HOOVERS, CASUAL RESTAURANTS INDUSTRY OVERVIEW, http://www.hoovers.com/industry-facts.casualrestaurants. 1443.html (last visited May 19, 2014) (printed query on file with author).

41. TLAPA ET AL., supra note 39, at 20.

42. U.S. CENSUS BUREAU, supra note 35.

43. Convenience Store Sales Topped $\$ 700$ Billion, ASS'N FOR CONVENIENCE \& FUEL RETAILING, Apr. 10, 2013, http://www.nacsonline.com/News/Daily/Pages/ND0410131 .aspx\#.UumsxPuymB4.

44. Id. The more precise estimate is $\$ 24,589,738$. 
Table 1

\begin{tabular}{|l|c|c|c|}
\hline & $\begin{array}{c}\text { Full-service } \\
\text { restaurants }\end{array}$ & $\begin{array}{c}\text { Limited- } \\
\text { service } \\
\text { restaurants }\end{array}$ & $\begin{array}{c}\text { Convenience } \\
\text { stores }\end{array}$ \\
\hline (a) Number in NYC & 7265 & 5427 & 554 \\
\hline (b) Revenues $(\$ 1000)$ & $\$ 7,484,339$ & $\$ 2,937,078$ & $\$ 241,787$ \\
\hline $\begin{array}{l}\text { (c) Fraction of revenues } \\
\text { from non-alcoholic } \\
\text { drinks }\end{array}$ & 0.06 & 0.04 & 0.113 \\
\hline (d) Profit margin & 0.90 & 0.90 & 0.90 \\
\hline $\begin{array}{l}\text { (e) Profits from sales of } \\
\text { non-alcoholic drinks } \\
\text { (\$1000) [(b) } \text { (c) } x(d)]\end{array}$ & $\$ 404,154$ & $\$ 105,735$ & $\$ 24,590$ \\
\hline $\begin{array}{l}\text { Total profits from } \\
\text { sales of non-alcoholic } \\
\text { drinks (assumed to be } \\
\text { sugary drinks) (\$1000) }\end{array}$ & & & \\
\hline
\end{tabular}

IV. BENEFITS OF THE RULE

This study estimates the benefits of sugary drink consumption by making a rough calculation of the monetized health benefits of curtailing sugary drink consumption. Most of the known adverse health outcomes stem from the contribution that sugary drinks make in making people obese. Treatment of obesity and the costs of obesity are expensive, but obesity imposes further costs if it persists, leading to Type 2 diabetes, ${ }^{45}$ coronary heart disease (CHD), and a variety of cancers. ${ }^{46}$ There is good reason to believe that communities of color would reap greater-thanaverage net health benefits. In New York State, obesity rates are $23.6 \%$ for non-Hispanic whites, but $26.3 \%$ for Hispanics and $32.5 \%$ for non-Hispanic blacks. $^{47}$ The overall rate of obesity in New York City is $22.1 \%{ }^{48}$ But

45. Type 2 diabetes is largely overlapping with diabetes mellitus. Melissa C. Stöppler, Diabetes Mellitus, MEDICINENET (last visited May 20, 2014), http://www. medicinenet.com/diabetes_mellitus/page5.htm \#type_2_diabetes.

46. See infra notes $48-\overline{49}$ and accompanying text.

47. Id.

48. N.Y. STATE DEP'T OF HEALTH, supra note 12, at 3. 
diabetes rates in New York City are more than twice as high for Hispanics and non-Hispanic blacks as they are for whites. ${ }^{49}$

This analysis undertakes two different approaches to estimating the health benefits of regulating sugary drink consumption. The first approach focuses on the two major negative health outcomes stemming from obesity: type 2 diabetes and CHD. Drawing on nationwide data from the Centers for Disease Control (CDC) on the costs of treating and stemming from type 2 diabetes and CHD, and on epidemiological data on the link between sugary drink consumption and the two diseases, national cost data is scaled down to New York City to determine the costs of type 2 diabetes and CHD suffered in New York City. These estimates are scaled down again to determine the fraction attributable to sugary drink consumption.

The second approach, instead of focusing on specific diseases resulting from sugary drink consumption, considers the costs of obesity generally, and attempts to attribute a fraction of the obesity problem from sugary drink consumptions. Nationwide data on the costs of obesity from the CDC is scaled down to its incidence for New York City. And as with the diabetes and CHD estimates, this figure is then scaled down again using epidemiological research to determine the fraction of those health costs attributable to sugary drink consumption.

Both of these approaches likely underestimate the health benefits of curbing sugary drink consumption, because of the other negative health outcomes that may be attributable to sugary drink consumption. For example, researchers are now investigating the possibility that sugary drink consumption leads to pancreatic cancer ${ }^{50}$ and endometrial cancer. ${ }^{51}$ Other causal pathways probably exist linking sugary drink consumption with negative health outcomes. But this part of the analysis focuses only on those for which a known and studied link exists between sugary drink consumption and negative health outcomes.

Both approaches also necessitate an additional calculation to estimate for the costs of premature mortality attributable to sugary drink consumption. CDC estimates of the national costs of obesity, type 2

49. N.Y.C. DeP'T OF HEALTH \& MENTAL Hygiene, Diabetes IN NEW YoRK CitY: PUBLIC HEALTH BURDEN AND DISPARITIES 1-2 (figure 1-8) (2007), available at http://www.nyc.gov/html/doh/downloads/pdf/epi/diabetes_chart_book.pdf.

50. See generally Eva S. Schemhammer et al., Sugar-Sweetened Soft Drink Consumption and Risk of Pancreatic Cancer in Two Prospective Cohorts, 14 CANCER EPIDEMIOLOGY, BIOMARKERS \& PREVENTION 2098 (2005).

51. Maki Inoue-Choi et al., Sugar-Sweetened Beverage Intake and the Risk of Type I and Type II Endometrial Cancer Among Postmenopausal Women, 22 CANCER EPIDEMIOLOGY, BIOMARKERS \& PREVENTION 2384 (2013). 
diabetes, and CHD do not include the costs of premature mortality. ${ }^{52}$ This is a very significant omission, because the cost of premature mortality potentially adds significantly to the benefit side of the ledger. If one adopts the EPA's value of a statistical life for mortality risk valuation - $\$ 7.4$ million ${ }^{53}$ - then one can imagine that the cost of even a relatively small number of deaths could swamp other benefit and costs considerations. Notwithstanding some uncertainty regarding the causal pathways to premature mortality, some linkage must certainly exist. The wellestablished linkages between sugary drink consumption and obesity, type 2 diabetes, and CHD, combined with the sheer number of cases and nontrivial mortality rates, very strongly suggest that sugary drink consumption produces some premature deaths. It would be a very curious omission to exclude these estimates.

\section{A. Approach One: Costs of Type 2 Diabetes and Coronary Heart Disease Attributable to Sugary Drink Consumption}

The first approach requires separate estimates of the cost of diabetes and of CHD. New York City does not collect this specific data, so an estimate of these costs for New York City must start with data at the national level, and then be scaled down to reflect New York City's share of national costs. New York City residents do not suffer diabetes or CHD at the same rate as Americans generally, so something more refined than a raw population-based scaling-down is called for. Once city-wide figures of total costs for diabetes and for CHD are estimated, some estimate of the fraction attributable to sugary drink consumption is needed. For both diabetes and for $\mathrm{CHD}$, some epidemiological studies producing something akin to dose-response relationships exist, and are combined in this analysis with consumption data to determine the fraction of cases of diabetes and CHD that are attributable to sugary drink consumption.

52. Ctrs. For Disease Control \& Prevention, National Diabetes Fact Sheet, 2011 (2011), available at http://www.cdc.gov/diabetes/pubs/pdf/ndfs_2011.pdf [hereinafter 2011 Fact Sheet]; CtrS. For Disease Control \& PREVention, HEarT DISEASE FACTS, http://www.cdc.gov/heartdisease/facts.htm (last visited May 20, 2014).

53. NAT'L CTr. for ENVTl. ECON., U.S. ENVTl. Prot. AgenCy, Frequently ASKED QUESTIONS ON MORTALITY RISK VALUATION, http://yosemite.epa.gov/ EE\%5Cepa\%5Ceed.nsf/webpages/MortalityRiskValuation.html (last visited May 20, 2014). 


\section{Diabetes}

\section{a. Direct and Indirect Costs}

The CDC reports that type 2 diabetes costs the United States $\$ 174$ billion annually. ${ }^{54}$ This estimate includes direct costs such as the cost of medical treatment, as well as indirect costs such as lost productivity costs. This estimate is derived from a 2008 study, ${ }^{55}$ and so is a bit dated. The study also warns that this is likely an underestimate because of a number of other hard-to-quantify costs. ${ }^{56}$ Nevertheless, this study provides a starting point for an estimate of the benefits of restricting sugary drink consumption. This CDC estimate does not include the costs of premature mortality. An estimate of the costs of premature mortality attributable to sugary drink consumption is undertaken in the latter part of this section.

The next question is what fraction of these costs occurs in New York City. A simple scaling-down by population of these national costs is inappropriate, because that would assume that type 2 diabetes occurs at the same rate in New York City as it does nationally. In fact, there is reason to suspect that New York City suffers diabetes at a rate lower than the national average. The CDC reports that based on an analysis of death certificates, 231,404 deaths occurred in 2010 nationally in which type 2 diabetes was a major or contributing factor. ${ }^{57}$ New York City reports that in 2010, 1711 deaths occurred from diabetes mellitus, or more commonly, type 2 diabetes. ${ }^{58}$ Death from type 2 diabetes takes place against the backdrop of overall deaths, and it is important to ascertain whether diabetes claims a larger or smaller fraction of lives in New York City than nationally. The answer is that New York City deaths from type 2 diabetes are about a third that of the national fraction of diabetes deaths to all deaths, ${ }^{59}$ suggesting that diabetes occurs with much less frequency in New

54. 2011 Fact Sheet, supra note 51.

55. See generally Am. Diabetes Ass'n, Economic Costs of Diabetes in the U.S. in 2007, 31 DIABETES CARE 596 (2008), available at http://care.diabetesjournals.org/ content/31/3/596.full.pdf + html.

56. Id. (noting that "[t]he actual national burden of diabetes is likely to exceed the $\$ 174$ billion estimate because it omits the social cost of intangibles such as pain and suffering, care provided by nonpaid caregivers, excess medical costs associated with undiagnosed diabetes, and diabetes-attributed costs for health care expenditures categories omitted from this study").

57. Id.

58. Stöppler, supra note 44.

59. In 2010,1711 New York City residents died from type 2 diabetes, out of 52,575 total New York City deaths, about 3.25 percent. 2011 Fact Sheet, supra note 51, at 7. Nationally, 231,404 Americans died from type 2 diabetes, out of 2,468,435 total 
York City than nationally. It is difficult to know whether this difference is due to differences in measurement, differences in definition, or if it is truly because New Yorkers suffer from type 2 diabetes much less than the average American. But it is impossible to ignore the discrepancy and make the assumption that the incidence of type 2 diabetes is the same in New York City as it is nationally. For this reason, this analysis uses the ratio of New York diabetes deaths to national diabetes deaths $(1711 / 231,404)$ as the estimate of New York City's share of national overall costs of type 2 diabetes. ${ }^{60}$ New York City's cost of type 2 diabetes is estimated to be roughly $\$ 1.29$ billion, ${ }^{61}$ out of the national total of $\$ 174$ billion. This excludes (for now) the costs of premature mortality from type 2 diabetes, which is calculated separately below. The ratio is only utilized here to make a reasonable estimate of how to scale down national costs (excluding death) to New York City costs (excluding death).

Table $2^{62}$

\begin{tabular}{|l|c|}
\hline (a) National cost of type 2 diabetes $(\$ 1000)$ & $\$ 174,000,000$ \\
\hline (b) National deaths from type 2 diabetes & 231,404 \\
\hline (c) New York City deaths from type 2 diabetes & 1711 \\
\hline $\begin{array}{l}\text { Cost to New York City from type 2 diabetes } \mathbf{( \$ 1 0 0 0 )}[\mathbf{( a )} \\
\mathbf{x}(\mathbf{c}) /(\mathbf{b})]\end{array}$ & $\mathbf{\$ 1 , 2 8 7 , 0 0 0}$ \\
\hline
\end{tabular}

Having estimated New York City's share of the national cost of type 2 diabetes, it remains to be estimated what fraction of these New York City-specific costs are attributable to sugary drink consumption, as opposed to other risk factors. Key to the analysis was Schulze et al. ${ }^{63}$ which studied the link between sugary drink consumption and type 2 diabetes in young and middle-aged women. This article is important because it breaks out sugary drink consumption by different levels of consumption and estimates the resulting risk relative to non-drinkers. ${ }^{64}$ This is the leading study which

American deaths, or 9.37 percent, almost three times the New York City fraction. CTRS. FOR DISEASE CONTROL \& PREVENTION, http://www.cdc.gov/nchs/fastats/ deaths.htm (last visited May 20, 2014).

60. Id.

61. The more precise figure is $\$ 1,286,555,116$. Am. Diabetes Ass'n., supra note 54, at 596 .

62. Id.

63. See generally Matthias B. Schulze et al., Sugar-Sweetened Beverages, Weight Gain, and Incidence of Type 2 Diabetes in Young and Middle-Aged Women, 292 JAMA 927 (2004).

64. Id. at 927 . 
attempts to establish, in rough terms, an effective dose-response relationship between sugary drink consumption and type 2 diabetes. ${ }^{65}$

The limitation of this study to one gender and certain age groups is obviously non-ideal. But careful and credible studies are often limited for purposes of studying a specific causal pathway. This analysis takes these studies as the best available estimates for the incremental effects of sugary drink consumption on type 2 diabetes risk.

This part of the study also produced some data-matching problems, as exploiting this kind of dose-response information requires some data on how many people consume how many sugary drinks. For New York City, three possible sources of estimates exist: (i) a New York Times poll conducted in August 2012; ${ }^{66}$ (ii) a CDC survey conducted from 2005 to $2008 ;^{67}$ and (iii) a New York City Community Health survey conducted from 2007 to $2009 .^{68}$ Ideally, data could identify how many New Yorkers consumed one to six drinks per week, one or two drinks per day, and two or more drinks per day. None of the surveys fit that bill. The most appropriate of these surveys is the CDC survey, because it provided a relationship between calories of consumption from sugary drinks each day with a percentage of the population. ${ }^{69}$ That is, given a particular amount of sugary drink consumption, the CDC data provided an estimate of how many people consumed that given amount. ${ }^{70}$ Reassuringly, these fractions, based on national survey data, appear to be fairly consistent with the available New York City consumption figures. This CDC consumption data is then combined with the dose-response relationships in Schulze et al. into estimates of how many New Yorkers were exposed to an increased risk over baseline of type 2 diabetes. In Table 3 below, this consumption

65. Id.

66. New York Times's Public Opinion Poll, N.Y. Times, Aug. 21, 2012, http://www. nytimes.com/interactive/2012/08/22/nyregion/22nyc-poll.html?ref =nyregion.

67. CYNTHIa L. OGDEN ET al., CONSUMPTION OF Sugar DRINKS IN THE UNITED STATES, 2005-2008, NAT'L CTR. FOR HEALTH STATISTICS DATA BRIEF No. 71 (2011), available at http://www.cdc.gov/nchs/data/databriefs/db71.pdf.

68. N.Y.C. DEP'T OF HEALTH \& MENTAL HYGIENE, CONSUMPTION OF SUGAR SWEETENED BEVERAGES IN NEW YORK CITY 2 (2011), available at http://www.nyc.gov/html/doh/downloads/pdf/epi/datatable4.pdf.

69. OGDEN ET AL., supra note 66, at 1-2.

70. Consumption data used for this study was obtained graphically, from a graph with calories of sugary drink consumption on the vertical axis, and the cumulative fraction of the population consuming that amount on the horizontal axis. Ogden et al., supra note 68, at 3 (fig. 3). The consumption data should thus be considered approximate. A twelve ounce can of Coca-Cola contains 140 calories, all of it from sugar. SUGAR STACKS, BEVERAGES, http://www.sugarstacks.com/beverages.htm (last visited May 20, 2014). 
data is used to estimate how many New York City residents consume these certain amounts of sugary drinks (in rows (a) and (b) in Table 3 below).

Schulze et al. estimated the relative risk (RR) ${ }^{71}$ of different levels of sugary drink consumption. ${ }^{72} \mathrm{RR}$ is the ratio of the heightened risk (due to exposure to the risky condition; in Schulze et al., drinking soda) to the baseline risk (the background risk faced by a population not exposed to the risk; in Schulze et al., non-soda drinkers or very low soda drinkers). ${ }^{73}$ These are expressed as the incidence of risk for each level of sugary drink consumption, ranging from less than one per month to more than one drink per day. ${ }^{74}$ RR can be translated into the amount of heightened risk, experienced annually, of diabetes produced by drinking sugary drinks. ${ }^{75}$ This in turn can be translated into an estimated number of individuals that will be diagnosed with diabetes as a result of sugary drink consumption. For a given consumption level $C$, the number of individuals with diabetes attributable to sugary drink consumption is given by the following formula:

Individuals with diabetes because of sugary drinks at level $C=$ individuals consuming at level $C \times\left(\mathrm{RR}_{C}-\mathrm{RR}_{\text {baseline }}\right) \mathrm{x}$ baseline risk

Schulze et al. found a total of 531 cases of diabetes among nondrinkers (those drinking less than once per week) from a total of about 570,000 person-years of study, meaning that in tracking the health of many individuals totaling 570,000 person-years of data, 531 times a fresh diagnosis of type 2 diabetes occurred. This suggests an annual baseline risk of 0.1 percent. ${ }^{76}$ That is, for any given year, the baseline risk is that one in one thousand will be diagnosed with type 2 diabetes. Utilizing these

71. For a population, the relative risk is the incidence rate of the diseased condition (in our study, type 2 diabetes or coronary heart disease) in the high-risk group (in our study, the incidence of diabetes or coronary heart disease among soda drinkers) divided by the incidence rate of the diseased condition in the non-risk group (in our study, nonsoda drinkers). See, e.g, Family Health Outcomes Project, Univ. of Cal., S.F., FHOP PLANNING GUIDE APP. III-B 156-62 (2010), available at http://hop.ucsf.edu/fhop/docs/pdf/pubs/pg_apxIIIB.pdf.

72. Schulze et al., supra note 62 , at 927,929 .

73. FAMILY HEALTH OUTCOMES PROJECT, supra note 70, at 155.

74. Schulze et al., supra note 62, at 932 (see the fourth line of table 3, "Multivariateadjusted RR"). Schulze et al. only state that respondents "were asked how often they had consumed a commonly used unit or portion size of each . . item." Id. at 928 . For lack of a better unit, a drink is assumed to be twelve ounces.

75. The Schulze et al. study only took place over a decade, so the risk measured is that of a diagnosis within ten years of a treatment. For purposes of this analysis, this risk is assumed to be equivalent to a lifetime risk, experienced annually. $I d$. at 927 .

76. Id. at 932 (see the first line of the first column of table 3). 
RR factors then, we can calculate the additional diabetes cases each year that are attributable to sugary drink consumption by totaling up the additional cases at the two consumption levels - two to six drinks per week and one or more drinks per day. That total is 2696 , about a quarter of all diabetes diagnoses each year.

Once an estimate is obtained for the additional diabetes cases attributable to sugary drink consumption, the New York City-wide costs of diabetes can be determined. That fraction of New York City-wide costs that are attributable to sugary drink consumption is the same fraction of diabetes cases attributable to sugary drink consumption divided by all diabetes cases. Table 3 sets out the calculation of type 2 diabetes costs attributable to sugary drink consumption in New York City, which is estimated to be $\$ 331$ million.

\section{Table 3}

\begin{tabular}{|c|c|c|}
\hline & 2-6/week & $1+/$ day \\
\hline $\begin{array}{l}\text { (a) Fraction of NYC residents consuming } \\
\text { sugary drinks of this amount (from CDC } \\
\text { data) }\end{array}$ & 0.2 & 0.3 \\
\hline $\begin{array}{l}\text { (b) Number of NYC residents consuming } \\
\text { sugary drinks of this amount ((a) } x \text { total } \\
\text { NYC pop of } 8,366,697)\end{array}$ & $1,667,339$ & $2,501,009$ \\
\hline $\begin{array}{l}\text { (c) Heightened risk of type } 2 \text { diabetes } \\
\text { diagnosis from consuming sugary drinks } \\
\text { (RR-1, from Schulze et al., Table } 3 \text {, line } \\
\text { 4) }\end{array}$ & 0.49 & 0.83 \\
\hline $\begin{array}{l}\text { (d) Baseline risk of type } 2 \text { diabetes } \\
\text { diagnosis (Schulze et al.) }\end{array}$ & 0.001 & 0.001 \\
\hline $\begin{array}{l}\text { (e) NYC residents diagnosed with type } 2 \\
\text { diabetes attributable to sugary drink } \\
\text { consumption each year [(b) } \mathrm{x} \text { (c) } \mathrm{x}(\mathrm{d})]\end{array}$ & 761 & 1935 \\
\hline $\begin{array}{l}\text { (f) Number of NYC residents diagnosed } \\
\text { with type } 2 \text { diabetes because of sugary } \\
\text { drink consumption each year (total of } \\
\text { figures from row (e) in both columns) }\end{array}$ & \multicolumn{2}{|c|}{2696} \\
\hline $\begin{array}{l}\text { (g) Baseline number of NYC residents } \\
\text { diagnosed with type } 2 \text { diabetes each year } \\
\text { ((d) X NYC pop of } 8,366,697)\end{array}$ & \multicolumn{2}{|c|}{7769} \\
\hline $\begin{array}{l}\text { (h) Total number of NYC residents } \\
\text { diagnosed with diabetes each year ((f) } \\
+(g))\end{array}$ & \multicolumn{2}{|c|}{10,465} \\
\hline
\end{tabular}




\begin{tabular}{|l|c|}
\hline (i) Cost of diabetes in NYC $(\$ 1000)$ & $\$ 1,286,555$ \\
\hline $\begin{array}{l}\text { Cost of diabetes in NYC attributable to } \\
\text { sugary drink consumption (\$1000) [(i) } \\
\mathbf{x ~ ( f ) / ( h ) ] ~}\end{array}$ & $\mathbf{\$ 3 3 1 , 4 2 9}$ \\
\hline
\end{tabular}

As noted above, however, the estimates of the national costs of type 2 diabetes undercount because they do not take into account the cost of premature mortality. The following section undertakes that calculation.

\section{b. Costs of Premature Death}

As noted above, New York City reports that 1711 deaths occurred from type 2 diabetes in $2010 .{ }^{77}$ In Table 2 above, a fraction was calculated to determine the number of diabetes cases attributable to sugary drink consumption out of all diabetes cases. That fraction was used to determine the amount of total diabetes costs that can be attributed to sugary drink consumption. This same fraction is now used to determine the number of diabetes deaths attributable to sugary drink consumption, over the total number of diabetes deaths of 1711. This is tabulated in Table 4 below, and multiplied by the value of a statistical life to estimate the cost of premature mortality from consuming sugary drinks.

Table 4

\begin{tabular}{|l|c|}
\hline $\begin{array}{l}\text { (a) Number of people dying from type 2 diabetes in } \\
\text { NYC }\end{array}$ & 1711 \\
\hline $\begin{array}{l}\text { (b) Baseline number of people diagnosed with type } 2 \\
\text { diabetes in NYC annually }\end{array}$ & 10,465 \\
\hline $\begin{array}{l}\text { (c) Number of people diagnosed with diabetes } \\
\text { attributable to sugary drink consumption }\end{array}$ & 2696 \\
\hline $\begin{array}{l}\text { (d) Number of NYC residents dying from type 2 } \\
\text { diabetes attributable to sugary drink consumption [(a) } \\
\text { x (c)/((c)+(b))] }\end{array}$ & 441 \\
\hline (e) EPA value of a statistical life (\$1000) & $\$ 7400$ \\
\hline $\begin{array}{l}\text { Cost of premature mortality in NYC from type 2 } \\
\text { diabetes attributable to sugary drink consumption } \\
\text { (\$1000) }\end{array}$ & $\mathbf{\$ 3 , 2 6 2 , 6 9 7}$ \\
\hline
\end{tabular}

77. Bureau of Vital Statistics, N.Y.C. Dep't of Health \& Mental Hygiene, SuMmary OF Vital Statistics 2010: THE City OF NEW YORK - POPULATION AND MORTALITY 42 (2011), available at http://www.nyc.gov/html/doh/downloads/ pdf/vs/ vs-population-and-mortality-report.pdf. 
Adding together the totals from Tables 3 and 4, the total cost of type 2 diabetes in New York City attributable to sugary drink consumption is thus roughly $\$ 3.6$ billion. This estimate is dominated by the estimated cost of premature mortality.

\section{c. A Lower-Bound Estimate of the Costs of Diabetes}

These results are sensitive to the value of the RRs reported by Schulze et al., and utilized in this analysis. If the RR is in reality lower than the central estimates used in this analysis, not only would the direct and indirect costs be overstated, but the number of premature mortality cases attributable to sugary drinks would be overstated as well; this is because the number of diabetes deaths attributable to sugary drinks is pegged to the number of diabetes cases attributable to sugary drinks, which depends on the RR.

To test the sensitivity of the results to the RR, the lower end of the 95\% confidence intervals from Schulze et al. were used to estimate a lower bound of type 2 diabetes costs, cases, and deaths. ${ }^{78}$ Using those values as a lower bound, the estimated cost of type 2 diabetes was about $\$ 176$ million, with the number of New York City diabetes deaths attributable to sugary drink consumption falling to 233 , yielding a premature mortality cost of about $\$ 1.73$ billion. The total cost of type 2 diabetes under that lowerbound scenario is about $\$ 1.9$ billion.

\section{Coronary Heart Disease}

\section{a. Direct and Indirect Costs}

The same calculation can be made for CHD costs attributable to sugary drink consumption. For CHD, the CDC cites a study estimating the direct and indirect costs of CHD at $\$ 108.9$ billion each year. ${ }^{79}$ This CDC

78. For those drinking two to six sugary drinks per week, the lower bound was 1.16 (as opposed to the central estimate of 1.49), and for those drinking one or more sugary drinks per day the lower bound was 1.42 (as opposed to the central estimate of 1.83). Schulze et al., supra note 62, at 932 (see the first line of the first column of table 3 ).

79. CTRS. For DisEASE CONTROL \& PREVENTION, supra note 51 (citing Paul A. Heidenreich et al., Forecasting the Future of Cardiovascular Disease in the United States: A Policy Statement from the American Heart Association, 123 CiRCULATION 933, 935, available at http://circ.ahajournals.org/content/123/8/933.long (see Tables 2 and 3 showing direct medical costs and lost productivity for coronary heart disease, adding up to $\$ 108.9$ billion in 2010)). 
estimate, like the one for type 2 diabetes, includes direct costs such as the cost of medical treatment, and indirect costs such as lost productivity costs, but does not include the cost of premature mortality.

Ascertaining the correct fraction of New York City CHD cases to national CHD cases poses definitional challenges not encountered when estimating the cost of type 2 diabetes. What the $\mathrm{CDC}$ refers to as $\mathrm{CHD}$ is not clearly referenced in New York City's report of vital statistics, which lists deaths from "[d]iseases of the heart." "W0 What can be estimated is the fraction of heart disease deaths generally, which the CDC estimates as 597,689 each year, ${ }^{81}$ of which CHD accounts for about $385,000 .^{82}$ If we assume that $\mathrm{CHD}$ accounts for approximately the same fraction of New York City deaths (out of all heart diseases), then an estimate for New York City CHD deaths can be obtained by multiplying this fraction with the total number of New York City heart disease deaths, which the City reports as $17,929 .{ }^{83}$ This yields an estimate of New York City CHD deaths of 11,549. The tabulation is set forth in Table 5 below.

\section{Table 5}

\begin{tabular}{|l|c|}
\hline $\begin{array}{l}\text { (a) Number of people dying from heart disease } \\
\text { nationally }\end{array}$ & 597,689 \\
\hline $\begin{array}{l}\text { (b) Approximate number of people dying from } \\
\text { CHD nationally }\end{array}$ & 385,000 \\
\hline $\begin{array}{l}\text { (c) Number of NYC residents dying from heart } \\
\text { disease }\end{array}$ & 17,929 \\
\hline $\begin{array}{l}\text { Approximate number of NYC residents dying } \\
\text { from CHD [(c) } x(\mathbf{b}) /(\mathbf{a})]\end{array}$ & $\mathbf{1 1 , 5 4 9}$ \\
\hline
\end{tabular}

As estimated, the fraction of New York City deaths from CHD is somewhat higher than the national CHD fraction; $22 \%$ of all deaths as opposed to $16 \%$ nationally. ${ }^{84}$ On the same reasoning as was utilized for our type 2 diabetes analysis, this difference is assumed to represent a differential between the rate at which New York City residents suffer and die from heart disease than the nation as a whole. New York City residents suffer more from CHD than does the national population generally. New

80. Bureau OF Vital STATISTiCS, supra note 76 , at 9 (see line 12 of table M1).

81. Ctrs. For Disease Control \& Prevention, Leading Causes of Death, http://www.cdc.gov/nchs/fastats/lcod.htm (last visited May 20, 2014).

82. CTRS. For DiSEASE CONTROL \& PREVENTION, supra note 51.

83. BUREAU OF VITAL STATISTICS, supra note 76 , at 9 (see line 12 of table M1).

84. The NYC fraction is $11,549 / 52,575=0.22$, while the national fraction is about $385,000 / 2,468,435=0.16$. 
York City's cost of CHD is thus estimated to be its proportional share of CHD deaths multiplied by the national cost of CHD. This calculation is set forth in Table 6 below, and is estimated to be $\mathbf{\$ 3 . 2 7}$ billion. ${ }^{85}$ And although mortality rates were used to calculate this fraction, the cost of premature mortality is excluded from this estimate.

Table 6

\begin{tabular}{|l|c|}
\hline (a) National cost of CHD $(\$ 1000)$ & $\$ 108,900,000$ \\
\hline (b) Approximate national deaths from CHD & 385,000 \\
\hline (c) Estimated New York City deaths from CHD & 11,549 \\
\hline $\begin{array}{l}\text { Cost to New York City from type 2 diabetes } \\
\text { (\$1000) [(a) } \mathbf{( c )} /(\mathbf{b})]\end{array}$ & $\mathbf{\$ 3 , 2 6 6 , 0 0 0}$ \\
\hline
\end{tabular}

Having estimated New York City's share of the national cost of type 2 diabetes and CHD, it remains to be estimated what fraction of these New York City-specific costs are attributable to sugary drink consumption, as opposed to other risk factors. While Schulze et al. provided an effective dose-response link between sugary drink consumption and risk of type 2 diabetes, Fung et al. conducted a study of the link between sugary drink consumption and CHD. ${ }^{86}$ Like Schulze et al., Fung et al. provides a relative risk (RR) ratio for different levels of sugary drink consumption, ${ }^{87}$ and is set forth in row (c) in Table 7 below. Like Schulze et al., Fung et al. is limited because it is limited to middle-aged women and younger women. Fung et al. provides a finer resolution than Schulze et al. because it estimates the RR for an additional, higher level of consumption (two or more drinks per day).

Using a calculation identical to the one used to estimate the type 2 diabetes diagnoses attributable to sugary drink consumption, I estimate the additional number of new CHD cases occurring each year at each of three levels of sugary drink consumption. Fung et al. found a total of 1606 new cases of CHD among non-drinkers (those drinking less than once per week) from a total of about $1,069,645$ person-years of study, yielding a baseline risk of about 0.15 percent. ${ }^{88}$ Using the RR factors from Fung et al., I

85. The more precise estimate is $\$ 3,266,695,723$.

86. Teresa T. Fung et al., Sweetened Beverage Consumption and Risk of Coronary Heart Disease in Women, 89 AM. J. CLINICAL NUTRITION 1037, 1040 (2009).

87. Id. at 1040 (see the fifth line of table 2, "Multivariate-adjusted").

88. Id. (see the third line of table 2) (noting that the number of cases of CHD among those drinking less than one per month or one to four drinks per month). The research subjects in Fung et al. were all screened for pre-existing cardiovascular disease, so that the RRs in their paper reflect the heightened risk of sugary drink consumption on a 
estimate the additional $\mathrm{CHD}$ cases each year that are attributable to sugary drink consumption by totaling up the additional cases at the three consumption levels - two to six drinks per week, one to two drinks per day, and two or more drinks per day. That total is 1515 , about a tenth of all CHD cases each year. Taking the fraction of CHD cases attributable to sugary drink consumption over all CHD cases yields an estimate of the share of NYC's CHD costs attributable to sugary drink consumption: about $\$ 353$ million.

Table 7

\begin{tabular}{|l|c|c|c|}
\hline & $2-6 /$ week & $1+/$ day & $2+/$ day \\
\hline $\begin{array}{l}\text { (a) Fraction of NYC residents } \\
\text { consuming sugary drinks (CDC) }\end{array}$ & 0.2 & 0.1 & 0.2 \\
\hline $\begin{array}{l}\text { (b) Number of NYC residents } \\
\text { consuming sugary drinks ((a) } \mathrm{x} \\
\text { pop of 8,366,697) }\end{array}$ & $1,667,339$ & 833,670 & $1,667,339$ \\
\hline $\begin{array}{l}\text { (c) Heightened risk of CHD from } \\
\text { consuming sugary drinks (Fung } \\
\text { et al.) }\end{array}$ & 0.08 & 0.27 & 0.39 \\
\hline $\begin{array}{l}\text { (d) Baseline risk of CHD each } \\
\text { year }\end{array}$ & 0.0015 & 0.0015 & 0.0015 \\
\hline $\begin{array}{l}\text { (e) Number of new CHD cases } \\
\text { attributable to sugary drink } \\
\text { consumption each year [(b) x (c) }\end{array}$ & 200 & 338 & 976 \\
\hline
\end{tabular}

completely "healthy" population (in terms of CHD). Arguably, the RRs from Fung et al. should be adjusted before applying it to the New York City population because clearly, a significant number of people in New York City already have cardiovascular disease. Whether the heightened risk for CHD posed by sugary drink consumption is the same for a population of completely "healthy" people as it is for a population that includes some with pre-existing cardiovascular disease is unclear. There does not appear to be any literature on the incremental risk of sugary drink consumption on an already unhealthy population. If one assumes, reasonably, that cumulative risks are greater, then the RRs reported in Fung et al. are under-estimates, and the health impacts of sugary drink consumption are greater than those estimated in this analysis. One can also ask why a fraction of the New York City population already has cardiovascular disease; if this analysis is reasonably accurate, some fraction of those cases of pre-existing cardiovascular disease in New York City were attributable to the consumption of sugary drinks. In other words, if one goes far back enough in time, the introduction of sugary drinks to New Yorkers was an exposure to a completely "healthy" population, in which case the RRs in Fung et al. are appropriate. Finally, given the very high benefit-to-cost ratios estimated in this paper, a slightly inaccurate $\mathrm{RR}$ is not likely to change the outcome significantly. 


\begin{tabular}{|c|c|}
\hline$x(d)]$ & \\
\hline $\begin{array}{l}\text { (f) Total number of new CHD } \\
\text { cases attributable to sugary drink } \\
\text { consumption each year (total of } \\
\text { figures from row (e) in all three } \\
\text { columns) }\end{array}$ & 1515 \\
\hline $\begin{array}{l}\text { (g) Baseline number of new CHD } \\
\text { case each year }\end{array}$ & 12,517 \\
\hline $\begin{array}{l}\text { (h) Total number of new CHD } \\
\text { cases each year }[(\mathrm{f})+(\mathrm{g})]\end{array}$ & 14,032 \\
\hline $\begin{array}{l}\text { (i) Annual cost of CHD in NYC } \\
(\$ 1000)\end{array}$ & $\$ 3,266,695$ \\
\hline $\begin{array}{l}\text { Cost of CHD in NYC } \\
\text { attributable to sugary drink } \\
\text { consumption }(\$ 1000)[(i) x \\
\text { (f) } /(h)]\end{array}$ & $\$ 352,605$ \\
\hline
\end{tabular}

\section{b. Costs of Premature Death}

Table 5 above sets out the estimate of New York City CHD deaths of 11,549. To estimate the fraction of this attributable to sugary drink consumption, a scaling-down calculation like the one employed for type 2 diabetes deaths is appropriate. This involves finding the fraction of CHD cases attributable to sugary drink consumption, and multiplying it by 11,549. Again employing the EPA figure for the value of a statistical life ( $\$ 7.4$ million), the resulting estimate of the cost of premature mortality in New York City attributable to sugary drink consumption is roughly $\$ \mathbf{9 . 2}$ billion.

\section{Table 8}

\begin{tabular}{|l|c|}
\hline (a) Number of people dying from CHD in NYC & 11,549 \\
\hline $\begin{array}{l}\text { (b) Baseline number of people diagnosed with CHD in } \\
\text { NYC annually }\end{array}$ & 12,517 \\
\hline $\begin{array}{l}\text { (c) Number of people with CHD attributable to sugary } \\
\text { drink consumption }\end{array}$ & 1515 \\
\hline $\begin{array}{l}\text { Number of NYC residents dying from CHD } \\
\text { attributable to sugary drink consumption (a) } x \\
\text { (c)/((c)+(b)) }\end{array}$ & $\mathbf{1 2 4 7}$ \\
\hline (e) EPA value of a statistical life (\$1000) & $\$ 7400$ \\
\hline $\begin{array}{l}\text { Cost of premature mortality in NYC from CHD } \\
\text { attributable to sugary drink consumption (\$1000) }\end{array}$ & $\mathbf{\$ 9 , 2 2 4 , 7 1 6}$ \\
\hline
\end{tabular}


Adding together the totals from tables 7 and 8 , the total cost of CHD in New York City attributable to sugary drink consumption is thus roughly $\$ 9.6$ billion.

\section{c. A Lower-bound Estimate of Costs of Coronary Heart Disease}

As with the type 2 diabetes analysis, it is worth exploring the possibility that the RRs reported in Fung et al. are too high. As in the estimate for diabetes costs, if we take the lower end of the $95 \%$ confidence intervals estimated by Fung et al., we can derive a lower bound for the direct and indirect costs and the premature deaths attributable to sugary drink consumption. ${ }^{89}$ These lower-bound estimates are $\$ 188$ million and $\$ 4.9$ billion, respectively, for a total lower-bound estimate of the CHD cost attributable to sugary drink consumption of about $\$ 5.1$ billion.

3. Total Direct and Indirect Costs, and Cost of Premature Deaths Attributable to Sugary Drink Consumption

Adding together the costs of type 2 diabetes and of CHD attributable to sugary drink consumption, the total health costs of sugary drink consumption is estimated to be roughly $\$ 13.2$ billion. Using the lower ends of the confidence intervals in both Schulze et al. and Fung et al. yields a total lower bound estimate of about $\$ 7$ billion. That is, if the actual RR for both diabetes and CHD are at the lower end of the confidence intervals reported by Schulze et al. and Fung et al., respectively, the estimate of the total health and premature mortality costs of sugary drink consumption is still about fourteen times higher than the potential lost profits.

These figures are clearly dominated by the estimated cost of premature mortality. Without the estimated cost of premature mortality, the central estimate of the total costs of type 2 diabetes and CHD would be just $\$ 684$ million. This is comparable to the compliance costs. But unless the number of deaths from type 2 diabetes and CHD attributable to sugary drink consumption are extremely small, the health benefits of curbing sugary drink consumption is very likely to be larger than the compliance costs.

89. Id. (see the fifth line of table 2). 


\section{B. Approach Two: Costs of Obesity Attributable to Sugary Drink Consumption}

The second approach is to estimate the costs of obesity in New York City attributable to sugary drink consumption. This analysis for this approach mimics that of the analysis for the first approach, in that a national estimate is scaled down to produce a New York City estimate, and then scaled down again to ascertain a fraction attributable to sugary drink consumption.

The CDC estimates that nationally, obesity-related healthcare costs add up to about $\$ 147$ billion per year. ${ }^{90}$ In addition to the $\$ 147$ billion in direct medical costs, a study commissioned by the Society of Actuaries found that obesity costs the United States $\$ 44$ billion in lost worker productivity due to death, $\$ 39$ billion in lost worker productivity due to temporary disability, and $\$ 65$ billion in lost worker productivity due to permanent disability. ${ }^{91}$ Omitting the costs of productivity loss due to death (because that is assumed to be a part of the costs of premature mortality), the total cost of obesity in the United States, exclusive of the costs of premature mortality, is $\$ 251$ billion annually. Again, scaling down by population might be a guess, but it would be worrisome because the obesity rate in New York City $\left(22.1 \%{ }^{92}\right)$ is lower than it is nationwide $\left(35.7 \%{ }^{93}\right)$. I estimate an obesity rate-adjusted population scaling down from national costs to New York City costs. In other words, I estimate the number of obese individuals nationally and in New York City, and assume that New York City's share of obesity costs are identical to its share of obese individuals. This estimate, set out in Table 9 below, yields a total estimated cost of obesity in New York City of roughly \$4.13 billion.

\section{Table 9}

(a) Cost of obesity in the United States (excluding lost productivity due to death, and excluding death)

90. Ctrs. For Disease Control \& Prevention, adult Obesity Facts, http://www.cdc.gov/obesity/ data/adult.html (last visited May 21, 2014); see also E.A. Finkelstein et al., Annual Medical Spending Attributable to Obesity: Payer- and Service-Specific Estimates, 28 HEALTH AFF. w822, w831 (2009).

91. Donald F. BEhan ET al., Soc'y OF ACtUARIES, OBESITY AND ITS RELATION TO MORTALITY AND MORBIDITY COSTS $39-41$ (2010), available at http://www.soa.org/ Files/Research/Projects/research-2011-obesity-relation-mortality.pdf.

92. N.Y. STATE DEP'T OF HEALTH, supra note 12, at 3.

93. CTRS. FOR DISEASE CONTROL \& PREVENTION, supra note 89. 


\begin{tabular}{|l|c|}
\hline (b) Population of the United States & $313,940,040$ \\
\hline (c) Population of New York City & $8,336,697$ \\
\hline (d) Obesity rate for the United States & 0.357 \\
\hline (e) Obesity rate for New York City & 0.221 \\
\hline $\begin{array}{l}\text { Cost of obesity for New York City } \\
\text { [(a) } \mathbf{x} \text { (e) } \mathbf{x} \text { (c)/(d) } \mathbf{x} \text { (b)] }\end{array}$ & $\mathbf{\$ 4 , 1 2 6 , 1 5 0}$ \\
\hline
\end{tabular}

The next step is to estimate the fraction of the New York-specific obesity problem that is attributable to sugary drink consumption. Babey et al. estimated the heightened risk of obesity resulting from sugary drink consumption for a California population. ${ }^{94}$ Babey et al. reported risk increases for two dose-response groups: those drinking "occasionally" (between one drink per week and one drink per day), and those drinking one or more sugary drinks per day. Those drinking occasionally had a $15 \%$ greater chance than nondrinkers of becoming overweight or obese, and those drinking one drink per day or more were $27 \%$ more likely to be obese or overweight. Since $22.1 \%$, or $1,842,410$, of New York City residents are obese, the task is to determine what fraction of that population is obese because of sugary drink consumption. Note that this line of analysis, following the results in Babey et al., does not produce annualized risk estimates, but rather lifetime risk estimates. This also assumes that the incremental risk of obesity is comparable as between California and New York City.

The baseline risk of obesity is not known because the $22.1 \%$ includes those New Yorkers that are consuming sugary beverages and thus expose themselves to a heightened risk of obesity from soda consumption. Following Babey et al., a heightened risk exposure - from drinking two to six drinks per week and one or more per day - can be expected to produce a proportionately higher number of cases: $15 \%$ and $27 \%$ more, respectively. The baseline rate is the rate for all New York City residents, on top of which some suffer heightened risk from consuming sugary drinks. In other words, the overall obesity rate of $22.1 \%$ is just the weighted average of all the risk groups combined, weighted by their fraction of the population and their heightened risk. The baseline rate is $\mathrm{R}$ in the following equation:

94. See generally SuSAN H. BABEy ET AL., UCLA CTR. FOR HEALTh POLICY RESEARCH, BubBling Over: SODA CONSUMPTION AND ITS LINK TO OBESITY IN CALIFORNIA (2009), available at http://www.publichealthadvocacy.org/PDFs/ Bubbling_PolicyBrief.pdf. 
New York city obesity rate $=0.221=(\mathrm{R} \times 0.5)+(\mathrm{R} \times 1.15 \times 0.2)+$ $(\mathrm{R} \times 1.27 \times 0.3)$

Solving for $\mathrm{R}$ yields a baseline obesity rate of 0.199 . Without sugary drinks, 199 New Yorkers out of 1000 would be obese; with sugary drinks, 221 are obese. From this an estimate the number of New York City residents that are obese because of their sugary drink consumption can be derived. The calculation is shown in Table 10 below. The cost of obesity in New York City, excluding premature mortality, is roughly $\$ 412$ million.

Table 10

\begin{tabular}{|c|c|c|c|}
\hline & $\begin{array}{l}\text { No sugary } \\
\text { drinks at all }\end{array}$ & 2-6/week & $1+/$ day \\
\hline $\begin{array}{l}\text { (a) Fraction of population } \\
\text { consuming ... }\end{array}$ & 0.5 & 0.2 & 0.3 \\
\hline $\begin{array}{l}\text { (b) Number of NYC residents } \\
\text { consuming ... }\end{array}$ & $4,168,349$ & $1,667,339$ & $2,501,009$ \\
\hline (c) Heightened risk of obesity & 0 & 0.15 & 0.27 \\
\hline (d) Baseline risk of obesity & 0.199 & 0.199 & 0.199 \\
\hline $\begin{array}{l}\text { (e) Risk of obesity [(d) x }(1+ \\
\text { (c))] }\end{array}$ & 0.199 & 0.229 & 0.253 \\
\hline $\begin{array}{l}\text { (f) Number of NYC residents } \\
\text { obese [(b) x (e)] }\end{array}$ & 829,167 & 381,417 & 631,826 \\
\hline $\begin{array}{l}\text { (g) Total number of NYC } \\
\text { residents obese }\end{array}$ & \multicolumn{3}{|c|}{$1,842,410$} \\
\hline $\begin{array}{l}\text { (h) Number of NYC residents } \\
\text { obese because of sugary drink } \\
\text { consumption }[(\mathrm{c}) \times(\mathrm{d}) \times(\mathrm{f})]\end{array}$ & 0 & 49,750 & 134,325 \\
\hline $\begin{array}{l}\text { (i) Total number of NYC } \\
\text { residents obese because of } \\
\text { sugary drink consumption }\end{array}$ & \multicolumn{3}{|c|}{184,075} \\
\hline $\begin{array}{l}\text { (j) Cost of obesity in NYC } \\
(\$ 1000)\end{array}$ & \multicolumn{3}{|c|}{$\$ 4,126,150$} \\
\hline $\begin{array}{l}\text { Cost of obesity in NYC } \\
\text { attributable to sugary drink } \\
\text { consumption }(\$ 1000)[(\mathrm{j}) \mathrm{x} \\
(\mathrm{i}) /(\mathrm{g})]\end{array}$ & \multicolumn{3}{|c|}{$\$ 412,243$} \\
\hline
\end{tabular}

But obesity is clearly linked with premature mortality, so an estimate of the costs of premature mortality from obesity attributable to sugary drink 
consumption is needed. As New York City does not include obesity as a cause of death in its mortality statistics, another estimate is needed.

Masters et al. estimate that unlike earlier studies, the fraction of deaths attributable to obesity is $18.2 \% .{ }^{95}$ An earlier estimate of the number of deaths attributable to obesity is from Allison et al., which estimates that approximately 280,000 deaths occur annually in the United States from obesity ${ }^{96}$ out of a total of about 2.4 million deaths per year. ${ }^{97}$ The previously authoritative Allison et al. estimate was about $11 \%$. Assuming that obese New York City residents will die at the same rate as those in the Masters et al. sample and the Allison et al. sample, these two estimates are used as bookends to estimate the number of deaths attributable to obesity.

New York City, however, has lower obesity rates than the United States as a whole $-22.1 \%$ as opposed to $35.7 \%$ nationally. These two bookend obesity death rates are thus scaled down by the ratio of the New York City obesity rate to the national obesity rate to arrive at an estimate of the New York City obesity death rate. Using the Masters et al. and the Allison et al. estimates, the New York City obesity death rates are estimated to be $11.3 \%$ on the high end and $7.2 \%$ on the low end. Again using the EPA value of a statistical life, the estimates of the cost of premature mortalities from obesity in New York City are shown in Table 11 below.

\section{Table 11}

\begin{tabular}{|l|c|c|}
\hline & $\begin{array}{c}\text { High estimate of } \\
\text { NYC death rate } \\
\text { from obesity } \\
\text { (Masters } \text { et al. })\end{array}$ & $\begin{array}{c}\text { Low estimate of } \\
\text { NYC death rate } \\
\text { from obesity } \\
\text { (Allison et al. })\end{array}$ \\
\hline $\begin{array}{l}\text { (a) Death rate attributable to } \\
\text { obesity }\end{array}$ & 0.113 & 0.072 \\
\hline (b) NYC deaths in 2010 & 52,575 & 52,575 \\
\hline $\begin{array}{l}\text { (c) NYC deaths in } 2010 \\
\text { from obesity }\end{array}$ & 5923 & 3811 \\
\hline
\end{tabular}

95. Ryan K. Masters et al., The Impact of Obesity on US Mortality Levels: The Importance of Age and Cohort Factors in Population Estimates, 103 AM. J. PUB. HEALTH, 1895, 1899 (2013).

96. David B. Allison et al., Annual Deaths Attributable to Obesity in the United States, 282 JAMA 1530, 1535 (1999).

97. The exact figure is $2,391,399$. CTRS. For Disease Control \& Prevention, NAT'L CTR. For Health Statistics, Deaths By Single Years of Age, Race, and SEX: UNITED STATES 19991 (1999), available at http://www.cdc.gov/nchs/data/ statab/VS00199_TABLE310.pdf. 


\begin{tabular}{|l|c|c|}
\hline (d) Value of statistical life & $\$ 7.4$ million & $\$ 7.4$ million \\
\hline $\begin{array}{l}\text { (e) Cost from premature } \\
\text { mortality from obesity in } \\
\text { NYC }\end{array}$ & $\$ 43.8$ billion & $\$ 28.2$ billion \\
\hline $\begin{array}{l}\text { (f) Number of obese } \\
\text { individuals in NYC }\end{array}$ & $1,842,410$ & $1,842,410$ \\
\hline $\begin{array}{l}\text { (g) Number of obese } \\
\text { individuals in NYC due to } \\
\text { sugary drink consumption }\end{array}$ & 184,075 & 184,075 \\
\hline $\begin{array}{l}\text { Cost of premature } \\
\text { mortality from obesity in } \\
\text { NYC attributable to } \\
\text { sugary drink consumption } \\
\text { [(e) } \mathbf{x}(\mathbf{g}) /(\mathrm{f}) \text { ] }\end{array}$ & $\mathbf{\$ 4 . 4 ~ b i l l i o n}$ & $\mathbf{\$ 2 . 8}$ billion \\
\hline
\end{tabular}

Adding to these figures the direct medical costs of treating obesity and the cost of lost productivity (derived in Table 10) produces an estimate of the total costs of obesity in New York City. Using Allison et al. and Masters et al. as bookends for a range of costs, the total costs of obesity in New York City are estimated to range from $\$ 3.2$ billion to $\$ 4.8$ billion. Similar to the analysis for the measure of the health costs through type 2 diabetes and for CHD, the cost-benefit analysis is largely animated by the cost of premature mortality.

\section{DISCUSSION AND CONCLUSION}

The estimates of costs and benefits are summarized in Table 12 below. The three columns in Table 8 pertain to two different methodologies, and for one methodology, a high and low estimate of the costs of premature mortality. Bear in mind that these are the total potential costs and benefits - the total amount of profits from sugary drink sales, and the total amount of health costs attributable to sugary drink consumption. To the extent that any policy seeks to curb sugary drink consumption and does so incompletely, the costs and benefits would both be smaller. Again, the assumption adopted for this analysis is that both would scale down proportionately. All benefits are in the form of reduced health costs, and are those in New York City only, and attributable to sugary drink consumption. 
Table 12 (all figures in billions of dollars, annually)

\begin{tabular}{|l|c|c|c|}
\hline & $\begin{array}{c}\text { Benefits } \\
\text { measured by } \\
\text { reduced type } \\
2 \text { diabetes } \\
\text { and CHD } \\
\text { costs }\end{array}$ & $\begin{array}{c}\text { Benefits } \\
\text { measured } \\
\text { by reduced } \\
\text { obesity } \\
\text { costs (high } \\
\text { mortality) }\end{array}$ & $\begin{array}{c}\text { Benefits } \\
\text { measured } \\
\text { by reduced } \\
\text { obesity } \\
\text { costs (low } \\
\text { mortality) }\end{array}$ \\
\hline $\begin{array}{l}\text { Total potential compliance } \\
\text { costs }\end{array}$ & $\mathbf{0 . 5 3}$ & $\mathbf{0 . 5 3}$ & $\mathbf{0 . 5 3}$ \\
\hline Cost of type 2 diabetes & 0.33 & & \\
\hline $\begin{array}{l}\text { Cost of premature mortality } \\
\text { from type 2 diabetes }\end{array}$ & 3.26 & & \\
\hline Cost of CHD & 0.35 & & \\
\hline $\begin{array}{l}\text { Cost of premature mortality } \\
\text { from CHD }\end{array}$ & 9.23 & & \\
\hline $\begin{array}{l}\text { Total potential benefits } \\
\text { (diabetes \& CHD) }\end{array}$ & 13.17 & & \\
\hline Cost of obesity & & 0.41 & 0.41 \\
\hline $\begin{array}{l}\text { Cost of premature mortality } \\
\text { from obesity }\end{array}$ & & 4.38 & 2.82 \\
\hline $\begin{array}{l}\text { Total potential benefits } \\
\text { (obesity) }\end{array}$ & & 4.79 & $\mathbf{3 . 2 3}$ \\
\hline
\end{tabular}

A number of caveats are in order. A number of analytical junctures give rise to the possibility of error in this analysis. The most significant and obvious sources of potential error include:

(a) revenues from sugary drink sales;

(b) profit margins from sugary drink sales;

(c) unaccounted-for profits from sugary drink sales;

(d) uncounted benefits of sugary drink sales other than profits, such as consumer's surplus in consuming sugary drinks;

(e) estimates of the national costs of type 2 diabetes, CHD, and obesity;

(f) inter-jurisdictional translations of data, and the resulting scalingdown of national costs to New York City costs;

(g) accuracy and application of sugary drink consumption data;

(h) inappropriate extension of Schulze et al., Fung et al., and Babey et al. to general populations; 
(i) inaccuracies stemming from the Schulze et al., Fung et al., and Babey et al. studies,

(j) epidemiological studies that provide the dose-response relationships; and

(k) estimates in the mortality rates of type 2 diabetes, $\mathrm{CHD}$, and obesity.

It was also surprising that the estimated health costs of sugary drink consumption were lower when considering its impact on obesity than it was in considering its impact through two specific causal pathways: (i) type 2 diabetes and (ii) CHD. Since obesity probably captures a broader spectrum of health risk factors, an estimate of the costs of obesity attributable to sugary drink consumption should wholly include the costs of attributable types 2 diabetes and CHD, and therefore be higher. Again, there a number of possible reasons for this possible anomaly. It could be that the CDC obesity estimates assume more modest linkages to CHD.

In the end, the ratios of benefits to costs are uniformly high. Even using the lower bound estimates of the RRs reported by Schulze et al. and Fung et al., the total costs, including the cost of premature mortality, are $\$ 7$ billion, yielding a $14: 1$ benefit-cost ratio. Using the lowest estimates of the costs of obesity ( $\$ 3.23$ billion) still yields a benefit-cost ratio of $6: 1$. And even if this analysis inappropriately discounted the profits from selling sugary drinks in New York City, the error is very unlikely to have bucked the $6: 1$ to $26: 1$ ratio of benefits to costs. These high ratios are driven by the cost of premature mortality. It is worth noting that even if the costs of premature mortality were to be excluded, a cost-benefit analysis of a total ban on sugary drink sales would yield roughly even costs and benefits. Even implausibly conservative assumptions about premature mortality, and even a very conservative value of a statistical life, however, would still produce a cost-benefit analysis that points in the direction of regulating the consumption of sugary drinks.

Despite the preliminary and rough nature of this analysis, it still seems reasonable to conclude that any attempt in New York City to reduce the consumption of sugary drinks would likely generate far more benefits (in the form of reduced health and mortality costs) than it would costs (in the form of reduced profits from the sales of sugary drinks). As noted above, there are a number of non-monetizable issues that shadow an analysis such as this one, but it would at least appear that New York City would be monetarily better off with some sugary drink regulation than without it. Hand-wringing over "freedom of choice" or "liberty of palate" seems superficial under these circumstances.

The significance of this finding - that the benefits of sugary drink regulation will generally outweigh the costs - extends far beyond New 
York City. New York City is not a representative city; it is less compelling to reduce sugary drink consumption in New York City than in other cities. The incidence of type 2 diabetes and obesity in New York City are both well below national averages, so there are fewer gains to be had from reducing sugary drink consumption. While New York City's obesity rate is $22.1 \%$, the 2010 obesity rate of the following cities was significantly higher: Chattanooga, TN - 30.4\%; Memphis, TN - 35.3\%; Detroit, MI $33.1 \%$; Dallas, TX - 33.8\%; and New Orleans, LA - 32.6\%. ${ }^{98}$ The sugary drink consumption problem could be greater in these areas, and could yield greater benefits in the form or reduced health costs.

Finally, it is worth noting that the nature of at least this rudimentary cost-benefit analysis is such that health costs and premature mortality are measured for some fictitious "average" adult individual. But given what we now know about obesity over a lifetime - that childhood obesity is almost certain to lead to adult obesity, and a lifetime of illness and lower life-expectancy ${ }^{99}$ - measures that attack childhood obesity are almost certain to yield greater benefits than those estimated in this analysis. Were a sugary drink restriction to apply to younger individuals, the benefit-tocost ratios would certainly be even higher than those produced by this analysis. Thus, if a cost-benefit analysis leads to the conclusion that sugary drink regulation is generally a desirable policy, then the cost-benefit analysis would apply with even greater force to a sugary drink restriction targeted at younger individuals.

Public discourse loudly celebrates a variety of liberties. And liberty is a difficult thing to price, depending on the contexts in which they are considered. But it seems that the liberty of palate has been celebrated in excess of its actual importance to society, and with utter disregard to the costs of that liberty. Liberty of palate, when it comes to the consumption of sugary drinks, offers a particularly stark example of how important it is to take a step back and attempt to consider the consequences of that liberty. It could well be that some liberties are much more expensive than they are important to the functioning of a society.

98. OBEstTy RATES For States, MEtro AREAS, Governing, http://www.governing.com/gov-data/obesity-rates-by-state-metro-area-data.html (last visited May 21, 2014).

99. See, e.g., Kolata, supra note 18. 


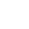

